\title{
Gerd-Rainer HORN, Western European Liberation Theology, 1924-1959. The First Wave
}

Oxford, Oxford University Press, 2008, 314 p.

\section{Michael Löwy}

\section{CpenEdition}

Journals

Édition électronique

URL : http://journals.openedition.org/assr/21146

DOI : $10.4000 /$ assr.21146

ISSN : 1777-5825

Éditeur

Éditions de l'EHESS

Édition imprimée

Date de publication : 31 décembre 2009

Pagination : $75-342$

ISBN : 978-2-7132-2218-4

ISSN : 0335-5985

\section{Référence électronique}

Michael Löwy, «Gerd-Rainer horn, Western European Liberation Theology, 1924-1959. The First

Wave », Archives de sciences sociales des religions [En ligne], 148 | octobre-décembre 2009, document 148-67, mis en ligne le 03 juin 2009, consulté le 21 septembre 2020. URL : http:// journals.openedition.org/assr/21146; DOI : https://doi.org/10.4000/assr.21146

Ce document a été généré automatiquement le 21 septembre 2020.

(C) Archives de sciences sociales des religions 


\title{
Gerd-Rainer HORN, Western European Liberation Theology, 1924-1959. The First Wave
}

Oxford, Oxford University Press, 2008, 314 p.

\author{
Michael Löwy
}

\section{RÉFÉRENCE}

Gerd-Rainer HORN, Western European Liberation Theology, 1924-1959. The First Wave, Oxford, Oxford University Press, 2008, 314 p.

1 Cet ouvrage pionnier est, à ma connaissance, le premier à proposer une vue d'ensemble de la gauche catholique européenne de la première moitié du siècle dernier. Il s'agit d'une contribution importante à la connaissance d'un phénomène sociohistorique important, qu'on n'avait abordé, jusqu'ici, que de façon partielle et limitée (à un pays ou un mouvement spécifique). Je reviendrai plus loin sur le titre, qui risque de susciter quelques malentendus.

Le livre n'a pas la prétention d'être exhaustif. Comme le reconnaît l'auteur, plusieurs personnages ou réseaux importants manquent à l'appel, comme le père Lebret et son groupe Économie et Humanisme. On pourrait noter plusieurs autres absences, notamment en France: Charles Péguy; le mouvement des Chrétiens socialistes des années trente ; Témoignage Chrétien et la Résistance ; les Chrétiens progressistes, liés au PCF ; la gauche de la CFTC, etc. On peut considérer que certains de ces cas de figure sont plus significatifs que d'autres inclus dans le livre; mais un certain choix était inévitable. Ce qui manque, c'est peut-être une définition plus précise du concept de " gauche catholique ", dont les frontières paraissent parfois, dans différents chapitres, un peu floues. La recherche concerne la France, la Belgique et l'Italie - accessoirement l'Allemagne - trois pays où la gauche catholique a connu un essor significatif à partir 
des années trente, pour atteindre son point le plus haut dans les années de la Libération (1944-46), et décliner par la suite.

3 Le point de départ du livre est l'Action Catholique, et en particulier la JOC (Jeunesse Ouvrière Chrétienne) fondée par le père Joseph Cardijn (Belgique) en 1924. Selon l'auteur, l'Action Catholique spécialisée, qui a connu une dynamique interne d'autonomisation et autodétermination, a été, jusqu'à la Seconde Guerre mondiale, surtout une affaire franco-belge. Ce sont les laïcs qui ont constitué le moteur du changement dans l'Église catholique, avec le soutien de quelques théologiens et intellectuels comme Yves Congar, Marie-Dominique Chenu, Emmanuel Mounier et Jacques Maritain. L'humanisme intégral, (1936), de ce dernier a été sans doute l'ouvrage le plus influent de l'avant-guerre, en proposant un idéal historique fondé sur la justice, la dignité et l'amour, capable de dépasser toute oppression de classe ou de caste. Si l'on trouve une certaine ouverture aux idées socialistes chez Maritain, Mounier ira bien plus loin, en proclamant que «le capitalisme doit être supprimé et remplacé par une organisation socialiste de la production et de la consommation» (Qu'est-ce que le personnalisme? 1946).

4 Après avoir passé en revue brièvement les éphémères expériences de courants de gauche dans la démocratie chrétienne en Allemagne (CDU) et en France (MRP), l'auteur s'intéresse au cas italien, où plusieurs réseaux vont se constituer au moment de la chute du fascisme (1943-45) : le groupe des « Dossetiens » - Giuseppe Dossetti, Amintore Fanfani, Giorgio La Pira - qui réussira a obtenir $35 \%$ des voix au Congrès de Venise de la Démocratie Chrétienne, en juin 1949, mais se dissoudra peu après; la Sinistra Cristiana(gauche chrétienne) de Felice Balbo et Franco Rodano, qui finira dans les rangs du parti communiste italien en 1945 ; le Parti Chrétien-Social, inspiré par Proudhon et Mounier, qui avait réussi à faire élire un député à l'Assemblée Constituante, en 1946, mais disparaîtra de la scène politique quelques années plus tard; et des prophètes iconoclastes locaux, comme Don Primo Mazzolari et Don Zeno Saltini, dont les tentatives d'organisation de réseaux de militants sociaux seront réprimées par le Vatican vers 1950-1951.

5 Les deux derniers chapitres concernent à nouveau le terrain franco-belge. Fondé en 1941, le Mouvement Populaire des Familles deviendra le plus important mouvement social à base de masse de la "première vague » du catholicisme de gauche français, notamment pendant les années 1944-1945, quand il atteindra quelque cent mille adhérents ; son équivalent belge - limité à la Wallonie francophone - n'aura jamais la même influence. Renforcé, à partir de 1943, par l'afflux de militants syndicaux et politiques de la gauche seculière (mise hors la loi par Vichy), le MPF connaîtra un mouvement d'autonomisation et dé-confessionalisation, se transformant de mouvement de l'apostolat laïc de l'Église en mouvement ouvrier indépendant. Malgré son déclin dans l'après-guerre, il jouera encore un rôle dans les années cinquante, en devenant une des composantes de la Nouvelle Gauche (et plus tard, du PSU). Soit dit entre parenthèses, cet épisode fort intéressant est seulement mentionné, mais pas vraiment étudié par l'auteur.

6 Suite à l'ouvrage retentissant de H. Godin et Y. Daniel, La France, pays de mission (1943), la Mission de France va développer un travail destiné à convertir les masses ouvrières " payennes ", en établissant des communautés chrétiennes de base dans les quartiers populaires et, peu après, en lançant l'expérience des prêtres-ouvriers ; une expérience analogue - bien plus réduite - aura lieu en Belgique, avec la Mission des Ouvriers de la 
Vierge des Pauvres. Comme dans le cas du MPF, les missionnaires finiront par adopter le point de vue des ouvriers, c'est-à-dire, en France dans l'après-guerre, de la CGT, sinon du PCF ; ainsi, pour l'équipe parisienne des prêtres-ouvriers, dans un document collectif envoyé au Cardinal Feltin en 1953, la lutte de classes est « une réalité brutale imposée à la classe ouvrière. C'est une lutte menée par le camp unifié des riches contre la classe ouvrière, aidé de tous côtés par les forces qui constituent ses piliers; pour le moment, aux yeux des ouvriers, l'Église est un de ces piliers ». Peu après, comme l'on sait, le Vatican mit fin à l'experience...

7 La majorité des cas étudiés dans ce livre concerne l'espace franco-belge; en fait, ces expériences sociales ont été beaucoup plus importantes en France qu'en Belgique - et plus radicales, en termes de gauche; le même chose vaut, à un degré encore plus évident, au sujet des intellectuels et théologiens catholiques de gauche. Comment expliquer cette place privilégiée du catholicisme de gauche en France, par rapport aux autres pays d'Europe? La question n'est pas vraiment abordée par l'auteur, mais elle mériterait de faire l'objet d'une recherche.

Dans sa conclusion, l'auteur rappelle que cette "première vague » du catholicisme de gauche a beaucoup contribué aux débats du Concile Vatican II, qui a été, à son tour, le point de départ d'une "deuxième vague ", non moins importante, qui dépassera l'Europe et aura un impact considérable en Amérique Latine. C'est dans ce continent que prendra son essor, après la conférence des évêques latino-américains de Medellin (1968), la Théologie de la Libération, dont les principaux représentants, comme Gustavo Gutierrez, ont étudié en Europe et ont été influencés par la "première vague » du catholicisme de gauche, notamment français et belge. L'auteur s'appuie ici sur un essai, publié par Jesus Garcia Ruiz et moi-même, sur les sources françaises du christianisme de la libération au Brésil (ASSR, 97, janv.-mars 1997, pp. 9-32); cependant, tandis que nous avions tenté de montrer à la fois la continuité et la rupture entre les deux phénomènes socioreligieux, et surtout la nouveauté radicale du «christianisme de gauche » brésilien, du point de vue d'un pays du Sud, l'auteur insiste sur les similarités et les convergences. Certes, il reconnaît que la théologie de la libération a surgi dans un contexte géographique, sociopolitique et culturel différent, mais il pense néanmoins qu'il s'agit essentiellement du même phénomène : d'où le titre du livre, La théologie de la libération d'Europe occidentale, 1924-1959. Il me semble que ce titre risque de créer plus de confusion que de clarté, en identifiant, de façon anachronique, deux réalités socioreligieuses profondément distinctes, parce qu'appartenant à deux univers historiques, économiques et sociopolitiques très différents : l'Europe d'avant le Concile, l'Amérique Latine d'après la révolution cubaine. Certes, les militants de la Jeunesse Universitaire Catholique (JUC) brésilienne se sont inspirés de Lebret ou Mounier (beaucoup moins de Maritain), mais ils ont emprunté ces idées de la gauche catholique française pour inventer en 1960-1961 quelque chose de nouveau, à partir de la perspective des peuples des pays dépendants, qui deviendra plus tard la théologie de la libération. Selon l'auteur, puisqu'on parle de théologie de la libération hors du contexte latino-américain, à propos du Sri Lanka ou des Philippines, pourquoi pas aussi l'Europe des années 1924-1959? Or, ces pays d'Asie où vivent d'importantes populations catholiques, appartiennent justement, comme l'Amérique Latine, au Sud de la planète, à la périphérie appauvrie et dominée du système-monde...

9 Quelles que soient les réserves que l'on peut avoir sur le titre, ce livre est sans doute un apport majeur à la compréhension des dynamiques internes des mouvements 
catholiques laïcs en Europe, et de la vitalité des courants de gauche dans la culture catholique de la première moitié du $\mathrm{xx}^{\mathrm{e}}$ siècle. 